\title{
The faecal flora of two patients with food-related irritable bowel syndrome during challenge with symptom-provoking foods
}

\author{
G. M. WYATT, C. E. BAYLISS, A. F. LAKEY, H. K. BRADLEY, J. O. HUNTER* and \\ V. ALUN JONES*
}

AFRC Institute of Food Research, Norwich Laboratory, Colney Lane, Norwich NR4 TUA and *Department of Gastroenterology, Addenbrookes Hospital, Hills Road, Cambridge CB2 200

\begin{abstract}
Summary. The faecal microbial flora of two patients with food-related irritable bowel syndrome was examined while they were on a diet excluding symptom-provoking foods, and then on a diet including such a food. The patients reacted differently to the challenge diet but some changes in faecal output, flora and short chain fatty acid content were seen.
\end{abstract}

\section{Introduction}

Irritable bowel syndrome (IBS) is a condition in which abdominal pain, diarrhoea, constipation or variability of bowel habit may be experienced. The involvement in some patients of non-immunological intolerance of specific foods has been demonstrated and symptoms may be controlled by diet management (Hunter and Alun Jones, 1985; Smith et al., 1985). It has been suggested that the bacterial gut flora are involved in this condition and changes in faecal flora of IBS patients have been shown previously (Balsari et al., 1982; Bayliss et al., 1986; Bradley et al., 1987) but not linked directly to specific foods.

Detailed comparisons of the faecal flora between IBS sufferers and healthy subjects are difficult to make because of the complexity of the normal flora and the marked differences found between those of different normal individuals (Holdeman et al., 1976). For a given individual, however, the rank order of species is usually stable (Moore et al., 1981), therefore any changes in flora due to symptom-provoking foodstuffs might be revealed by challenge with that food. In the pilot study reported here, two patients were hospitalised and maintained on a diet free of their symptom-causing food until given a blind challenge of that food. The bacterial flora of the faeces and other faecal parameters were analysed during the different dietary periods.

Received 14 Sep. 1987; accepted 2 Jan. 1988.

\section{Patients and methods}

\section{Case histories}

Patient P3. A 25-year-old man presented 9 months before the study with a 5-year history of recurrent abdominal pain and a 6-month history of sporadic diarrhoea. At presentation he complained of alternating diarrhoea and constipation, abdominal bloating, flatulence and lack of energy. Blood count, urea, electrolytes and liver function tests, and jejunal biopsy were normal. No pathogens were found in his faeces. An elimination diet at Addenbrookes Hospital identified bread and coffee as symptom-provoking foods. No antibiotics had been taken for at least 3 months before the study.

Patient P7. A 25-year-old woman presented one year previously with a 5-year history of abdominal bloating and pain, vomiting, and diarrhoea. These had become much worse since a bout of Campylobacter gastroenteritis about 4 months previously. Radiographs of stomach, gall bladder and colon, rectal biopsy, urea, electrolytes and liver function tests were normal; no pathogens were found in her faeces. A psychiatrist found no psychopathology. An elimination diet identified several symptomprovoking foods, including rice, wheat, onion and eggs.

For both patients, double blind challenges confirmed their food intolerances and both were well whilst on exclusion diets.

\section{Diets during the studies}

Whilst in hospital, the patients ate a diet free of known symptom-provoking foods, except when challenged as detailed below.

Patient P3. The normal diet included two servings per day of a soup thickened with rice flour $(100 \mathrm{~g} /$ day $)$. On days 3-6 of the study, soup thickened with wheat flour was substituted. The patient was not aware of the change. 
Table I. Symptoms present in two patients during challenge with symptom-provoking foods

\begin{tabular}{|c|c|c|c|c|c|c|}
\hline \multicolumn{3}{|c|}{ Patient P3 } & \multicolumn{4}{|c|}{ Patient P7 } \\
\hline Day & Headache & Bloating & Day & $\begin{array}{l}\text { General } \\
\text { condition }\end{array}$ & Headache & Bloating \\
\hline 1 & 0 & 0 & 1 & $0 \cdot 0$ & $3 \cdot 3$ & 0.0 \\
\hline 2 & 0 & 0 & 2 & $2 \cdot 0$ & 0.7 & 0.0 \\
\hline $3^{*}$ & 0 & 0 & $3^{*}$ & $3 \cdot 4$ & $5 \cdot 4$ & 5.0 \\
\hline $4 \ddagger$ & ++ & 0 & $4 \ddagger$ & 0.6 & $2 \cdot 2$ & $1 \cdot 1$ \\
\hline 5 & ++ & + & $5^{+}$ & $6 \cdot 4$ & 0.0 & 10.0 \\
\hline $6 \dagger$ & 0 & 0 & $6 \dagger$ & $2 \cdot 4$ & 0.0 & 5.0 \\
\hline 7 & 0 & +++ & 7 & 5.7 & 5.0 & $3 \cdot 4$ \\
\hline $8 \S$ & + & 0 & $8 \S$ & 1.3 & 0.0 & 0.0 \\
\hline 9 & 0 & 0 & 9 & 8.3 & 10.0 & 0.0 \\
\hline 10 & 0 & 0 & & & & \\
\hline
\end{tabular}

Symptoms scored as follows-

Patient P3: $0=$ not present $+=$ mild $++=$ moderate $+++=$ severe

Patient P7: score is position on a scale of $0-10$, from normal to extremely unwell (general condition), or from absent to severe (headache and abdominal bloating); mean of scores for two 12-h periods per day.

* First meal of challenge diet.

+ Last meal of challenge diet.

$\ddagger$ First challenge markers present in faeces.

$\S$ First post-challenge markers present in faeces.

Radio-opaque markers were fed in opaque capsules $(2 x$ 10 markers per day) employing different shapes before, during and after feeding the challenge diet.

Patient P7. The normal diet during the study included two portions of rye flakes $(100 \mathrm{~g} /$ day $)$, served as a breakfast cereal with orange juice instead of milk as the patient was also intolerant of milk. During days 3-6 of the study, wheat flakes were substituted for the rye flakes; the two flakes were visually indistinguishable. Radioopaque markers were fed as above.

Each patient recorded symptoms experienced, and in the case of patient $P 7$, filled in a questionnaire which included marking a $10 \mathrm{~cm}$ bar for severity of symptoms (table I).

\section{Measurement of stool parameters}

All stools passed were collected by the patients in plastic bags, weighed and placed in an anaerobic cabinet containing an atmosphere of $\mathrm{N}_{2} 85 \%, \mathrm{H}_{2} 10 \%$ and $\mathrm{CO}_{2}$ 5\% within 5-15 min of being passed. Viable counts of anaerobes and aerobes in the faeces were performed as previously described (Bradley et al., 1987). For selected stools, all of the colonies from the highest dilution showing growth on both the aerobic and anaerobic plates were characterised as previously described (Bradley et al., 1987).

Samples of faeces were dried to a constant weight at $100^{\circ} \mathrm{C}$ to determine moisture content. The remainder of each stool was frozen at $-20^{\circ} \mathrm{C}$ for subsequent analysis of short chain fatty acid (SCFA) content by the method of Bayliss and Houston (1985). The presence of markers was determined by radiographic examination of the stool samples. The samples between the first to contain challenge markers and the last before the appearance of the post-challenge markers (inclusive) were taken to represent the challenge diet stools.

\section{Results}

Both patients displayed symptoms during the studies (table I). The non-specific symptoms of headache or general condition did not correlate well with diet; however, the specific symptom of abdominal bloating, with which both patients had presented, was markedly associated with the period of the challenge diet. Patient P3 passed 14 stool samples and patient P7 passed 20 stool samples during the study period. Total faecal weight was much greater for patient P7. Simple linear regression lines were fitted to the cumulative faecal output by the computerised statistical package MINITAB (Pennsylvania State University).

For both patients there was a slight increase in faecal output whilst on the challenge diet (figure). The stool frequency (mean number of stools $/ 24 \mathrm{~h}$ ) was higher during the period of the challenge diet for both patients (normal diet P3 1.1, P7 2.0; challenge diet P3 2.0, P7 2.5). Neither patient had 


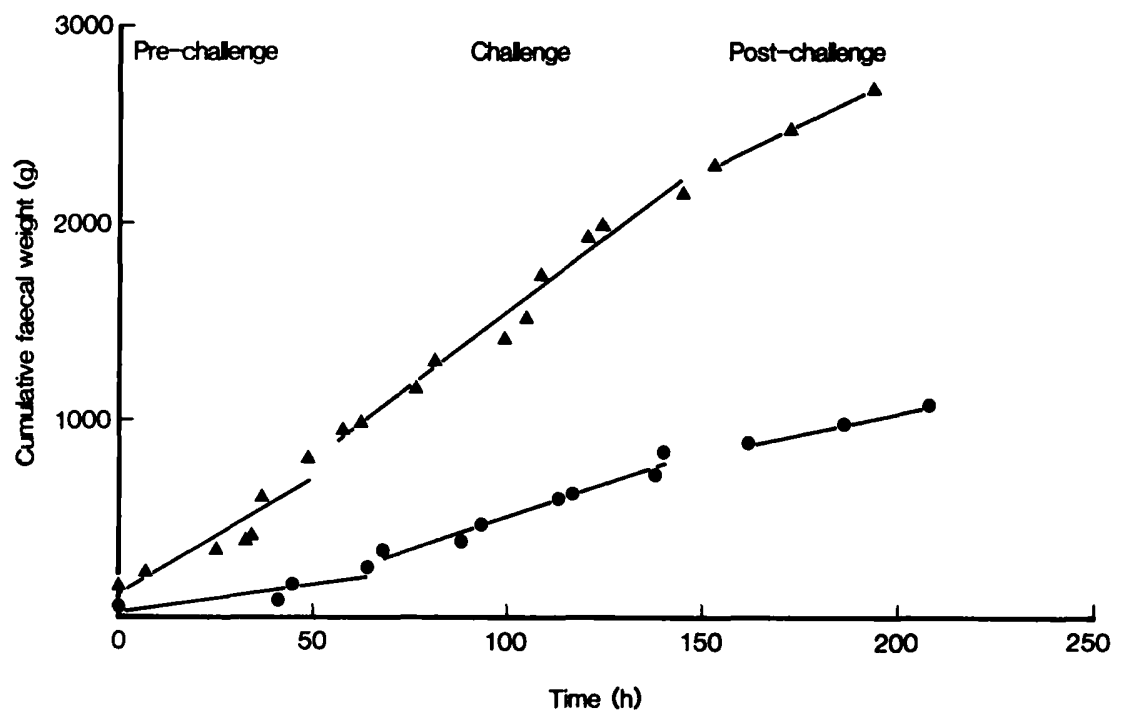

Figure. Cumulative faecal output of the patients during the study. Time zero was taken as the time of passage of the first stool. Simple regression lines are fitted to the data. $\mathbf{O}=$ patient $\mathbf{P} 3 ; \mathbf{\Delta}=$ patient $\mathbf{P 7}$.

diarrhoea and there was no difference in moisture content of the faeces between normal and challenge diet periods (table II).

For patient $\mathrm{P} 3$, the first challenge diet markers appeared in stool sample 5 (day 4) and the first postchallenge diet markers in sample 12 (day 8 ); for patient $\mathrm{P} 7$, the first challenge markers appeared in stool sample 8 (day 4) and the first post-challenge markers in sample 18 (day 8 ).

No significant diet-related differences in bacterial viable counts were seen in either patient (table
II); there was little change with diet in the major species present in the faeces, although in patient P7 the anaerobic gram-positive lactic acid bacteria (Bifido-bacterium and Lactobacillus spp.) increased from $21 \%$ to $43 \%$ of the flora during the challenge diet (table III). The major SCFAs present in both patients were acetic, propionic and $n$-butyric acids; for patient P3 the concentrations of all three increased markedly during the challenge diet and this difference was significant for acetic and proprionic acids (table II).

Table II. Changes in faecal parameters in two patients during challenge with symptom-provoking food

\begin{tabular}{|c|c|c|c|c|c|c|c|c|c|}
\hline \multirow[b]{2}{*}{ Patient } & \multirow[b]{2}{*}{ Diet } & \multirow{2}{*}{$\begin{array}{l}\text { Number of } \\
\text { samples } \\
\text { tested }\end{array}$} & \multicolumn{2}{|c|}{$\begin{array}{l}\text { Viable counts } \\
\left.\text { (mean (SE) } \log _{10} \mathrm{cfu} / \mathrm{g}^{*}\right)\end{array}$} & \multirow{2}{*}{$\begin{array}{c}\text { Anaerobe: } \\
\text { aerobe } \\
\text { ratio }\end{array}$} & \multicolumn{3}{|c|}{$\begin{array}{l}\text { Short chain fatty acids } \\
\left(\text { mean }(\mathrm{SE}) \mu \mathrm{mol} / \mathrm{g}^{*}\right)\end{array}$} & \multirow{2}{*}{$\begin{array}{c}\text { Moisture } \\
\text { content } \\
\text { (mean }(\mathrm{SE}) \%)\end{array}$} \\
\hline & & & aerobes & anaerobes $\dagger$ & & acetic & propionic & $n$-butyric & \\
\hline P3 & Challenge & 7 & $\begin{array}{c}9 \cdot 16 \\
(0 \cdot 27) \\
\text { NS } \\
8 \cdot 42 \\
(0 \cdot 15)\end{array}$ & $\begin{array}{c}11 \cdot 38 \\
(0 \cdot 11) \\
\text { NS } \\
11 \cdot 25 \\
(0.05)\end{array}$ & $166: 1$ & $\begin{array}{c}374 \\
(62 \cdot 1) \\
\mathrm{p}<0.05 \\
653 \| \\
(75.6)\end{array}$ & $\begin{array}{c}15.0 \\
(2.5) \\
p<0.05 \\
30.9 \| \\
(4.5)\end{array}$ & $\begin{array}{c}18.1 \\
(3.4) \\
\text { NS } \\
33.4 \| \\
(6 \cdot 8)\end{array}$ & $\begin{array}{l}71 \cdot 3 \\
(1 \cdot 8) \\
\text { NS } \\
74 \cdot 7 \\
(2 \cdot 6)\end{array}$ \\
\hline P7 & Challenge & 10 & $\begin{array}{c}8.7 \ddagger \\
(0.08) \\
\text { NS } \\
8.98 \S \\
(0.13)\end{array}$ & $\begin{array}{l}11 \cdot 27 \ddagger \\
(0.06) \\
\text { NS } \\
11 \cdot 38 \S \\
(0.04)\end{array}$ & $372: 1$ & $\begin{array}{c}289 \\
(33 \cdot 6) \\
\text { NS } \\
292 \\
(21 \cdot 3)\end{array}$ & $\begin{array}{l}42 \cdot 2 \\
(5 \cdot 8) \\
\text { NS } \\
38 \cdot 5 \\
(4 \cdot 6)\end{array}$ & $\begin{array}{c}69.2 \\
(15.9) \\
\text { NS } \\
89.2 \\
(13.9)\end{array}$ & $\begin{array}{c}79 \cdot 6 \\
(0 \cdot 71) \\
\text { NS } \\
80 \cdot 1 \\
(0.71)\end{array}$ \\
\hline
\end{tabular}

NS = no significant difference; values were compared by Student's $t$ test.

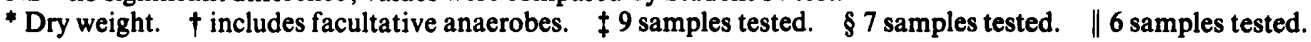


Table III. Approximate composition of faecal flora in two patients during challenge with symptom-provoking foods

\begin{tabular}{|c|c|c|c|c|}
\hline \multirow[b]{3}{*}{ Principal genera present } & \multicolumn{4}{|c|}{ Percentage ${ }^{*}$ of faecal flora } \\
\hline & \multicolumn{2}{|c|}{ Patient P3 } & \multicolumn{2}{|c|}{ Patient P7 } \\
\hline & $\begin{array}{c}\text { Normal } \\
\text { diet }\end{array}$ & $\begin{array}{c}\text { Challenge } \\
\text { diet }\end{array}$ & $\begin{array}{c}\text { Normal } \\
\text { diet }\end{array}$ & $\begin{array}{c}\text { Challenge } \\
\text { diet }\end{array}$ \\
\hline AEROBES & $(7) \dagger$ & $(7) \dagger$ & $(8) \dagger$ & $(7) \dagger$ \\
\hline Streptococcus spp. & 24 & 12 & 75 & 80 \\
\hline Escherichia coli & 54 & 53 & 8 & 12 \\
\hline Micrococcus spp. & 0 & 16 & 3 & 0 \\
\hline Enterobacter spp. & 12 & 1 & 5 & 0 \\
\hline Others & 10 & 18 & 9 & 8 \\
\hline ANAEROBES & $(2) \dagger$ & $(2) \dagger$ & $(2) \dagger$ & $(3)+$ \\
\hline Bacteroides spp. & 20 & 26 & 28 & 36 \\
\hline Bifidabacterium spp. & 3 & 13 & 8 & 18 \\
\hline Eubacterium spp. & 19 & 23 & 4 & 2 \\
\hline Lactobacillus spp. & 19 & 12 & 13 & 25 \\
\hline gram-negative cocci & 12 & 5 & 0 & 0 \\
\hline gram-positive cocci & 0 & 0 & 9 & 0 \\
\hline others (not identified) & 20 & 21 & 38 & 19 \\
\hline facultative aerobes & 7 & 0 & 0 & 0 \\
\hline
\end{tabular}

* Figures represent mean percentages of the total numbers of colonies isolated from either aerobic or anaerobic cultures.

$\uparrow$ Number of faecal samples examined.

\section{Discussion}

The patients in this study responded differently to blind challenge with symptom-provoking foods, patient $\mathbf{P} 3$ reacting more strongly than patient $\mathbf{P 7}$. The increased faecal output and stool frequency during challenge compares with the work of Eastwood et al. (1984), who found higher mean daily stool weights and frequencies in a group of IBS patients than in age- and sex-matched controls. Although no differences in the density of viable bacteria in the faeces were detectable during our studies, the increased output of faeces whilst on the challenge diet increased the total number of bacteria, and hence bacterial activity, in the colonic lumen. Furthermore, although only small differences in the balance of bacterial species present were seen, with each patient tending to maintain their own particular rank order of species, significant differences in SCFA content of faeces in patient $P 3$ suggest either that bacterial metabolism altered during the challenge diet or that the processes of absorption by the colonic mucosa changed.

Both patients had a lower than usual ratio of anaerobic:aerobic bacteria in their faeces. This is generally >1000:1 (Mitsuoka, 1982) in normal subjects, and in our experience $>10000: 1$ (Bradley et al., 1987); this higher level of aerobes seems to be characteristic of some IBS patients (Bayliss $e t$ al., 1984, 1986; Bradley et al., 1987) and was found to correlate positively with a score of symptoms in IBS patients in whom the condition arose after abdominal surgery (Bayliss et al., 1986). Balsari et al. (1982) noted the appearance of aerobic genera (Pseudomonas, Enterobacter) in IBS patients not encountered in normal subjects, although in those patients the syndrome was not necessarily foodrelated. In our work, two of the seven stool specimens from patient $\mathrm{P} 3$ during the challenge diet period contained Micrococcus spp., in one stool constituting $>80 \%$ of isolates; this organism is normally only a minor component of faecal flora (Finegold et al., 1974).

It is clear from this pilot study and other work that changes in some aspects of the gut flora are associated with food-related IBS, particularly in the metabolic activity of the fiora or the presence of increased numbers of aerobic species. These changes may move in different directions in different individuals, but it is not certain whether they are the cause of the symptoms or just reflect other biological alterations. Further studies with larger numbers of patients are needed. The possi- 
bility that pharmacologically active metabolites, derived from food residues by an altered flora in the colon of IBS patients, are the cause of the symptoms should be also investigated.

\section{REFERENCES}

Balsari A, Ceccarelli A, Dubini F, Fesce E, Poli G 1982 The faecal microbial population in the irritable bowel syndrome. Microbiologica 5: 185-194.

Bayliss C E, Bradley H K, Alun Jones V, Hunter J O 1986 Some aspects of colonic microbial activity in irritable bowel syndrome associated with food intolerance. Annali dell Istituo Superiore di Sanita 22:959-964.

Bayliss C E, Houston A P 1985 The effect of guar gum on microbial activity in the human colon. Food Microbiology 2:53-62.

Bayliss C E, Houston A P, Alun Jones V, Hishon S, Hunter J O 1984 Microbiological studies on food intolerance. Proceedings of the Nutrition Society 43:16A.

Bradley H K, Wyatt G M, Bayliss C E, Hunter J O 1987 Instability in the faecal flora of a patient suffering from food-related irritable bowel syndrome. Journal of Medical Microbiology 23:29-32.

Eastwood M A, Walton B A, Brydon W G, Anderson J R 1984 Faecal weight, constituents, colonic motility and lactose
We thank G. P. Evans, K. Hamand, N. Horn, A. P. Slade, S. G. Wharf and A. M. Wilson for help with parts of the study. H. K. Bradley and A. F. Lakey were funded by the East Anglian Regional Health Authority. Special thanks are due to the patients concerned for their co-operation in the studies.

tolerance in the irritable bowel syndrome. Digestion 30:712.

Finegold S M, Attebery H R, Sutter V L 1974 Effect of diet on human faecal fiora: comparison of Japanese and American diets. American Journal of Clinical Nutrition 27: 1456-1469.

Holdeman L V, Good I J, Moore W E C 1976 Human faecal flora: variation in bacterial composition within individuals and a possible effect of emotional stress. Applied and Environmental Microbiology 31 :359-375.

Hunter J O, Alun Jones V 1985 Studies on the pathogenesis of irritable bowel syndrome produced by food intolerance. In : Read N W (ed) Irritable Bowel Syndrome. Grune and Stratton Inc., pp 185-189.

Mitsuoka T 1982 Recent trends in research on intestinal flora. Bifidobacteria and Microflora 1 :3-24.

Moore W E C, Cato E P, Good I J, Holdeman L V 1981 The effect of diet on the human faecal flora. In: Bruce W R et al. (eds) Banbury Report 7: Gastrointestinal cancer: endogenous factors. Cold Spring Harbour Laboratory, New York, pp 11-24.

Smith M A, Youngs G R, Finn R 1985 Food intolerance, atopy and irritable bowel syndrome. Lancet 2: 1064 . 